\title{
Monthly Oral Ibandronate Is Well Tolerated and Efficacious in Postmenopausal Women: Results from the Monthly Oral Pilot Study
}

\author{
Jean-Yves Reginster, Katie M. Wilson, Etienne Dumont, Bernard Bonvoisin, and Joanne Barrett \\ Unité d'Exploration du Metabolisme de l'Os et du Cartilage (J.-Y.R.), University of Liège, B-4020 Liège, Belgium; F. \\ Hoffmann-La Roche Ltd. (K.M.W., B.B., J.B.), Basel, CH-4070, Switzerland; and GlaxoSmithKline (E.D.), Collegeville, \\ Pennsylvania 19426
}

\begin{abstract}
Context: Ibandronate, a potent, nitrogen-containing bisphosphonate developed for intermittent administration in postmenopausal osteoporosis, aims to overcome current adherence issues with daily and weekly oral bisphosphonates through once-monthly oral dosing.
\end{abstract}

Objective: The purpose of this study was to investigate the safety, pharmacodynamics, and pharmacokinetics of once-monthly oral ibandronate.

Design: A randomized, 3-month, double-blind, placebo-controlled, phase I study (Monthly Oral Pilot Study) was conducted.

Setting: The study was conducted at five clinical trial centers in the United Kingdom and Belgium.

Patients or Other Participants: Subjects were postmenopausal women (age, $55-80 \mathrm{yr} ; \geq 3$ yr post menopause; $\mathrm{n}=144$ ).

Intervention(s): Once-monthly oral ibandronate 50, 100, or $150 \mathrm{mg}$ or placebo was used. After the first cycle, the $50-\mathrm{mg}$ arm was split, with participants continuing on either 50 or $100 \mathrm{mg}$.
Main Outcome Measure(s): Primary outcome measures were safety, serum and urinary C-telopeptide (CTX), and serum ibandronate $\mathrm{AUC}_{0-\infty}$.

Results: Once-monthly oral ibandronate was well tolerated, with a similar overall and upper gastrointestinal safety profile to placebo. Once-monthly ibandronate was also highly effective in decreasing bone turnover; substantial reductions from baseline in serum CTX $(-56.7 \%$ and $-40.7 \%$ in the 150 - and $100-\mathrm{mg}$ arms, respectively; $P<$ 0.001 vs. placebo) and urinary CTX $(-54.1 \%$ and $-34.6 \%$, respectively; $P<0.001 \mathrm{vs}$. placebo) were observed at $\mathrm{d} 91$ ( $30 \mathrm{~d}$ after the final dose). Analysis of the area under the effect curve (d 1-91) for change from baseline (percent $\times$ days) in serum CTX and urinary CTX indicated a dose-response relationship. The $\mathrm{AUC}_{0-\infty}$ for ibandronate increased with dose but not in a dose-proportional manner.

Conclusions: These findings indicate a potential role for oncemonthly oral ibandronate in the treatment of postmenopausal osteoporosis. (J Clin Endocrinol Metab 90: 5018-5024, 2005)
STEOPOROSIS IS A chronic, yet often silent, systemic skeletal disease, characterized by low bone mass and microarchitectural deterioration of bone tissue, leading to increased bone fragility and susceptibility to fracture. It is a serious condition that, as a result of its most debilitating symptom, the fragility fracture, has an immense impact on society (1). Conservative estimates suggest that more than one third of adult women will sustain one or more osteoporosis-related fractures in their lifetime $(1,2)$, resulting in substantial disability (3-5), mortality (6-9), and health care expenditure $(3,10,11)$.

Although effective therapies are available for its management, osteoporosis, like other chronic, largely asymptomatic

First Published Online June 21, 2005

Abbreviations: Ae, Amount of drug excreted in urine; AUC, area under the curve; AUEC, area under the effect curve; BMD, bone mineral density; $\mathrm{CI}$, confidence interval; $\mathrm{CL}_{\mathrm{R}}$, renal clearance; $\mathrm{C}_{\max }$ maximum observed plasma concentration; CTX, C-telopeptide; DSRC, data safety review committee; GI, gastrointestinal; ITT, intent-to-treat; MOBILE, Monthly Oral Ibandronate in Ladies (study); MOPS, Monthly Oral Pilot Study; PD, pharmacodynamic; PK, pharmacokinetic; PP, per-protocol; $\mathrm{sCTX}$, serum CTX; $\mathrm{t}_{1 / 2}$, plasma elimination half-life; $\mathrm{uCTX}$, urinary CTX. JCEM is published monthly by The Endocrine Society (http://www. endo-society.org), the foremost professional society serving the endocrine community. diseases, is associated with poor therapeutic adherence. Indeed, recent studies indicate that both compliance and persistence with current osteoporosis medications are suboptimal (12-18). A negative impact on therapeutic outcomes has also been observed, with nonadherent patients showing smaller increases in bone mineral density $(\mathrm{BMD})(16,17)$, smaller decreases in bone turnover $(17,19)$, and reduced antifracture efficacy $(15,18)$ compared with adherent counterparts.

Adherence to therapy can be enhanced by decreasing the frequency and complexity of dosing (20). In osteoporosis management, patient preference for less complex dosing is illustrated by the recent introduction and rapid uptake of weekly oral bisphosphonate regimens (21-24). Prescription claims database studies [IHCIS (Integrated Healthcare Information Services, Inc.) (12); NDCHealth (13)] highlight the positive impact of less frequent bisphosphonate dosing on therapeutic adherence, with improved 1-yr persistence rates observed with the weekly vs. daily dosing schedule (54.5 vs. 36.9 and 44.2 vs. $31.7 \%$, respectively). However, although weekly administrations go some way to enhancing therapeutic adherence, these findings also indicate that persistence rates remain suboptimal $(12,13)$.

Ibandronate is a potent, nitrogen-containing bisphospho- 
nate that aims to overcome current adherence issues with oral bisphosphonates through the provision of less frequent dosing regimens, such as once monthly. Unlike other bisphosphonates, the high potency of ibandronate (25), together with its favorable tolerability profile, allow dosing with extended intervals, beyond the weekly dosing concept. A recent, randomized, double-blind, placebo-controlled, phase III, fracture-prevention study [oral iBandronate Osteoporosis vertebral fracture study in North America and Europe (BONE)] demonstrated the antifracture efficacy and safety of daily $(2.5 \mathrm{mg})$ and intermittent $(20 \mathrm{mg}$ every other day for 12 doses, followed by more than 2 months drug-free interval every 3 months) oral ibandronate regimens in postmenopausal women with osteoporosis (26). After $3 \mathrm{yr}$, daily and intermittent oral ibandronate significantly reduced the risk of new vertebral fractures, by $62 \%(P=0.0001)$ and $50 \%$ $(P=0.0006)$, respectively, relative to placebo (difference between treatments, $P=0.2785$ ). Significant and substantial increases in BMD and decreases in biochemical markers of bone turnover were also observed. Ibandronate was well tolerated, with a similar safety profile to placebo.

In light of these findings and the beneficial effects for adherence with less frequent bisphosphonate administrations, we performed a randomized, double-blind, placebocontrolled, phase I, dose-ranging study [Monthly Oral Pilot Study (MOPS)] to establish the feasibility of once-monthly dosing with oral ibandronate in postmenopausal women, the findings of which are reported herein.

\section{Subjects and Methods}

\section{Participants}

All participants were women, 55-80 yr old, who were postmenopausal for at least $3 \mathrm{yr}$ at enrollment. No specific lumbar spine BMD inclusion criteria were set. Participants were excluded from the study if they had: a dietary calcium intake less than $500 \mathrm{mg} / \mathrm{d}$; received drugs known to affect bone metabolism within 6 months, treatment with bisphosphonates or fluoride within 12 months or for more than $2 \mathrm{yr}$, or any investigational drug within $30 \mathrm{~d}$; undergone bilateral oophorectomy; or diseases or disorders known to influence bone metabolism, including chronic gastrointestinal (GI) or liver disease, malignant disease within $10 \mathrm{yr}$, diagnosed breast cancer within $20 \mathrm{yr}$, alcoholism, primary hyperparathyroidism, Paget's disease, osteomalacia, or active thyroid disease without treatment. Participants with esophageal abnormalities, active gastric or duodenal ulcers, renal impairment, vitamin D deficiency, allergy to bisphosphonates, or serum calcium levels at least 2.6 or less than $2.0 \mathrm{mmol} /$ liter were also excluded. Certain concomitant medications and supplements were allowed but had to be recorded on the case report form. All participants provided written informed consent; the study complied with the requirements of the Declaration of Helsinki and with the International Conference on Harmonization Good Clinical Practice and was approved by the Ethics Committees at the participating centers.

\section{Study design}

Conducted in five centers, of which four were in the United Kingdom and one in Belgium, MOPS was a randomized, double-blind, placebocontrolled, phase I, dose-ranging study of the safety, pharmacodynamics (PDs), and pharmacokinetics (PKs) of monthly oral ibandronate in postmenopausal women. At enrolment, participants were randomized to receive three cycles of monthly oral (every $30 \mathrm{~d}$ ) placebo or 50, 100, or $150 \mathrm{mg}$ ibandronate (Fig. 1). Because flu-like symptoms have been observed in a minority of patients receiving nitrogen-containing bisphosphonates, the $50-\mathrm{mg}$ arm was split into two arms $(\mathrm{n}=18)$ after the first dosing cycle to separate the effects of dose and first-time treat-

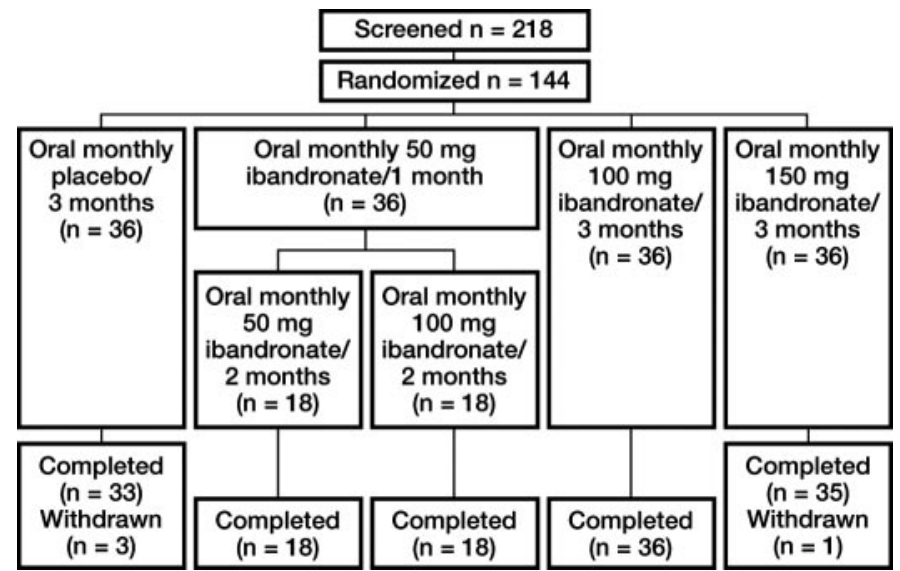

Fig. 1. Study design and patient disposition in MOPS.

ment, with participants continuing on either 50 or $100 \mathrm{mg}$ ibandronate for the remaining cycles (Fig. 1).

Study medication was supplied in monthly blister packages containing three film-coated tablets (50 $\mathrm{mg}$ ibandronate or placebo) to the desired dose. All tablets were taken with $240 \mathrm{ml}(8 \mathrm{oz})$ plain water after an overnight fast of at least $6 \mathrm{~h}$. Participants were instructed to maintain an upright posture and continue fasting for at least $60 \mathrm{~min}$ after dosing. A standardized breakfast was taken $1 \mathrm{~h}$ after drug administration.

\section{Dose selection}

The ibandronate regimens evaluated in MOPS were selected on the basis of prior clinical experience (26) and clinical trial simulation (27). In $\mathrm{BONE}$, daily and intermittent oral ibandronate regimens of the same cumulative dose (225-240 mg every 3 months) provided comparable (no significant difference) reductions in the risk of new vertebral fractures and changes in BMD and biochemical markers of bone turnover. However, similar to studies of oral daily and weekly bisphosphonates $(21,22)$, and most likely a result of the extension of the dosing interval, a nominal, yet consistent, advantage was observed in favor of the daily regimen. Thus, in MOPS, it was considered reasonable to explore the efficacy and safety of oral doses beyond the cumulative monthly dose provided by the daily regimen (i.e. $>75 \mathrm{mg}$ ). Simulated biomarker responses for a range of monthly oral ibandronate regimens supported this conclusion (27).

\section{Randomization}

A centralized randomization procedure was used to assign participants to the respective treatment arms. However, given the limited experience with the investigational regimens in the study population, a three-step randomization procedure was used to gradually expose small numbers of participants to increasing doses of oral ibandronate. In this way, additional participants were only exposed to higher doses of oral ibandronate after the safety of the lower doses had been established. To this end, a data safety review committee (DSRC) was established from statisticians and clinicians who were not involved in the study. The DSRC was not blinded to treatment, and they monitored adverse events during each step. After each step, the DSRC authorized the exposure of more participants to higher doses of oral ibandronate. In the first step, participants were allocated only to placebo or 50 or $100 \mathrm{mg}$ ibandronate. In the second step, nine participants were allocated to $150 \mathrm{mg}$ ibandronate. In a third step, a further 27 participants were allocated to $150 \mathrm{mg}$ ibandronate.

\section{Study endpoints}

Safety parameters were: adverse events (including abnormal laboratory findings), and episodes of flu-like symptoms (e.g. fatigue, fever, chills, myalgia, and arthralgia). Serum laboratory safety parameters (hematology, biochemistry) were measured at screening and on d 1, 2, $5,31,35,61,62,65$, and 91 . PTH vs. albumin/calcium was measured at 
d 1 and 91.25-Hydroxycholecalciferol was measured at screening. Urine safety laboratory parameters were measured at screening and at d 1, 2, 61,62 , and 91 . Using a supplied thermometer, participants recorded their body temperature on d 1-5, 31-35, and 61-65.

The primary PD endpoint was relative change (percent) from baseline in concentrations of the C-telopeptide (CTX) of the $\alpha$-chain of type 1 collagen, a sensitive biochemical marker of bone resorption, in serum (sCTX) and urine ( $\mathrm{uCTX}$ ) at d 91. An exploratory analysis of the area under the effect curve (AUEC; $d$ 1-91) for relative change (percent $X$ days) in SCTX and uCTX was also performed. sCTX concentrations were measured in blood samples taken between 0800 and $1000 \mathrm{~h}$, after an overnight fast. uCTX concentrations were assessed in the second morning spot urine. Blood and urine samples were taken on d 1 (baseline), $9,17,23,31,61,69,77,83$, and 91. In addition, sCTX was measured on d 5 and 65. Concentrations of sCTX and UCTX (creatinine-corrected) were quantified (centrally) using an automated analyzer (ELECSYS 2010; Roche Diagnostics, Basel, Switzerland) and an ELISA (CrossLaps EIA kit; Roche Diagnostics), respectively.

The primary PK parameter for the estimation of systemic exposure was the area under the concentration time curve $\left(\mathrm{AUC}_{0-\infty}\right)$ for ibandronate in serum after the first dose in each group. Secondary PK parameters were: maximum observed plasma concentration $\left(\mathrm{C}_{\text {max }}\right)$; amount of drug excreted in urine $(\mathrm{Ae})$; renal clearance $\left(\mathrm{CL}_{\mathrm{R}}\right)$, calculated as $\mathrm{Ae}_{0-48}$ $\mathrm{h}$ divided by $\mathrm{AUC}_{0-48} \mathrm{~h}$; and plasma elimination half-life $\left(\mathrm{t}_{1 / 2}\right)$, calculated as $\ln (2) / \mathrm{k}_{\mathrm{el}}$ where $\mathrm{k}_{\mathrm{el}}$ is the apparent elimination rate determined by linear regression analysis of terminal data points. Blood samples for PK analysis were taken at $0,0.5,1,2,4,6,8,12,24,48,72,96,144$, and $192 \mathrm{~h}$ post dose after the first cycle only and urine samples at $0-6,6-12$, $12-24,24-48,48-72$, and $72-96 \mathrm{~h}$ post dose after the first and third cycles. Concentrations of ibandronate in serum and urine were determined by ELISA and gas chromatography/mass spectrometry, respectively, at a centralized laboratory (MDS Pharma Services, Zurich, Switzerland AG). PK parameters were estimated from model-independent methods (Winnonlin Professional version 3.1 and version 4.0, Pharsight, Mountain View, CA; Excel 97 SR-2, Microsoft, Redmond, WA) using established equations.

\section{Statistical analyses}

Safety. All patients who received at least one dose of study medication, whether withdrawn prematurely or not, were included in the safety analysis. The frequency, incidence, intensity, and causal relationship of all adverse events were tabulated. Laboratory safety variables were considered evaluable in those patients who received treatment and for whom safety values for the first visit and at least one follow-up visit during the treatment period were available.

PDs. The primary analysis of PD variables was based on the per-protocol (PP) population. Patients were included in the PP analysis if none of the inclusion criteria were violated, none of the exclusion criteria held true for which an effect on the variable might be assumed, they were compliant to therapy, and at least one bone resorption parameter was determined at baseline and at least one thereafter. To support the findings from the PP analysis, PD variables were also analyzed on an intent-totreat (ITT) basis. Patients were included in the ITT analysis if they were randomized to therapy and bone markers were followed up at least once after baseline. For the ITT population only, if the d-91 result was missing for any bone resorption marker, the last nonmissing postbaseline observation was used for the d-91 analysis. An extended Wilcoxon ranksum test was used to establish differences in median relative change (percent) and AUEC (percent $\times$ days; d 1-91) for sCTX and uCTX between the treatment arms.
PKs. A one-way ANOVA with factor dose was applied to dose-normalized and log-transformed values of $\mathrm{AUC}_{0-\infty}$, the primary PK variable. Based on the results of this ANOVA, the systemic exposure at the 100-mg and 150-mg doses was expressed as a ratio to the value obtained at the $50-\mathrm{mg}$ dose. By estimating mean ratios together with $95 \%$ confidence intervals (CI) for the two higher doses, and because $\mathrm{AUC}_{0-\infty}$ values were normalized for dose, dose-proportionality of systemic exposure could be evaluated. An identical analysis was performed for the secondary PK variable $C_{\max }$. An exploratory ANOVA with the factors treatment, subject nested in treatment and period was applied to dose-normalized and log-transformed values of Ae (cycles 1 and 3) to estimate intrasubject variability.

\section{Results \\ Disposition and baseline characteristics}

Of the 218 participants screened, 144 were randomized to treatment and received at least one dose of study medication, forming the ITT/safety population (Fig. 1). Of these participants, 130 met the criteria for inclusion in the PP population. Overall, four participants withdrew from the study: three due to adverse events (two in the placebo group and one in the 150-mg ibandronate group), and one (placebo group) because continuous clotting prevented blood samples from being taken.

The baseline characteristics of the ITT/safety population are summarized in Table 1 . Treatment arms were well balanced in terms of age, weight, and height. However, in the absence of specific BMD inclusion criteria, some participants were clearly osteoporotic (T-score $\leq-2.5$ ), others osteopenic (T-score $\leq-1$ to -2.5$)$, and others normal (T-score $\geq-1$ ), with respect to BMD at the lumbar spine.

\section{Safety}

Overall safety. At the studied doses, once-monthly oral ibandronate was well tolerated, with a safety profile similar to placebo (Table 2). Overall, no apparent relationship between adverse events and dose was observed. No differences were observed among study arms in the overall incidence of adverse events, drug-related adverse events, and overall or drug-related adverse events resulting in withdrawal (Table 2 ). Adverse events were mostly mild to moderate in intensity and typical of the bisphosphonate class. No serious adverse events or deaths were reported (Table 2). No clinically relevant changes in laboratory safety parameters were observed in the active treatment arms relative to placebo. In particular, there were no changes in hepatic or renal function, serum calcium, or PTH. The number of patients experiencing flulike symptoms was similar across the placebo and active treatment groups and did not increase with increasing ibandronate dose $[20,8,6,17$, and 16 patients in the placebo; 50, $50 / 100,100$, and $150 \mathrm{mg}$ ibandronate treatment arms $(\mathrm{n}=36$, $18,18,36$, and 36), respectively]. The majority of participants

TABLE 1. Mean (range) baseline patient characteristics (ITT/safety population)

\begin{tabular}{|c|c|c|c|c|c|}
\hline & Placebo $(\mathrm{n}=36)$ & $50 \mathrm{mg}(\mathrm{n}=18)$ & $50 / 100 \mathrm{mg}(\mathrm{n}=18)$ & $100 \mathrm{mg}(\mathrm{n}=36)$ & $150 \mathrm{mg}(\mathrm{n}=36)$ \\
\hline Age (yr) & $63.9(55-79)$ & $65.7(61-74)$ & $61.7(55-77)$ & $64.1(56-77)$ & $63.3(55-79)$ \\
\hline Weight (kg) & $68.9(54-105)$ & $67.6(54-86)$ & $73.9(54-108)$ & $69.2(52-101)$ & $69.0(54-100)$ \\
\hline Height $(\mathrm{cm})$ & $161.0(151-174)$ & $161.3(148-179)$ & $161.2(148-175)$ & $162.0(151-176)$ & $161.3(152-174)$ \\
\hline $\begin{array}{l}\text { Lumbar spine } \\
\text { BMD T-score }\end{array}$ & $-1.2(-3.4$ to +2.2$)$ & $-1.9(-2.9$ to -1.0$)$ & $-0.3(-2.3$ to +1.1$)$ & $-1.1(-3.7$ to +1.8$)$ & $-0.8(-3.0$ to +2.1$)$ \\
\hline
\end{tabular}


TABLE 2. Overall summary of safety [ITT/safety population; n (\%)]

\begin{tabular}{|c|c|c|c|c|c|}
\hline & $\begin{array}{l}\text { Placebo } \\
(\mathrm{n}=36)\end{array}$ & $\begin{array}{c}50 \mathrm{mg} \\
(\mathrm{n}=18)\end{array}$ & $\begin{array}{c}50 / 100 \mathrm{mg} \\
(\mathrm{n}=18)\end{array}$ & $\begin{array}{c}100 \mathrm{mg} \\
(\mathrm{n}=36)\end{array}$ & $\begin{array}{l}150 \mathrm{mg} \\
(\mathrm{n}=36)\end{array}$ \\
\hline Any adverse event & $34(94)$ & $18(100)$ & $17(94)$ & $33(92)$ & $32(89)$ \\
\hline Any drug-related adverse event ${ }^{a}$ & $3(8)$ & $3(17)$ & 0 & $2(6)$ & $2(6)$ \\
\hline Any serious adverse event & 0 & 0 & 0 & 0 & 0 \\
\hline Any adverse event leading to withdrawal & $2(6)$ & 0 & 0 & 0 & $1(3)$ \\
\hline Any drug-related adverse event leading to withdrawal ${ }^{a}$ & 0 & 0 & 0 & 0 & 0 \\
\hline Any adverse event leading to death & 0 & 0 & 0 & 0 & 0 \\
\hline
\end{tabular}

${ }^{a}$ Adverse event considered "probably" related to treatment.

reporting flu-like symptoms experienced a single event in isolation.

Upper GI tolerability. The total number of upper GI adverse events occurring within $3 \mathrm{~d}$ of treatment, and thus most likely to be a reflection of treatment effect, was comparable across the treatment arms $(6,0,4,8$, and 9 events in the placebo; 50, 50/100, 100, and 150-mg arms, respectively). Regarding upper GI adverse events occurring at any time during the study, and not just within $3 \mathrm{~d}$ of therapy, a slightly higher number of events occurred in the 100- and 150-mg arms (15 events per arm) relative to the other arms $(12,3$, and 11 events in the placebo; 50- and 50/100-mg arms, respectively). The majority of these adverse events were mild in intensity.

\section{$P D s$}

Baseline concentrations of sCTX and UCTX did not differ appreciably among groups. The median concentrations in the five groups ranged from $0.42-0.47 \mathrm{ng} / \mathrm{ml}$ for sCTX and from 175.7-212.3 $\mu \mathrm{g} / \mathrm{mmol}$ for uCTX. The smallest and largest values (all groups) were 0.06 and $1.33 \mathrm{ng} / \mathrm{ml}$, respectively, for sCTX and 22.4 and $546.8 \mu \mathrm{g} / \mathrm{mmol}$ for uCTX.

At the studied doses, once-monthly oral ibandronate was effective in reducing bone turnover, as demonstrated by substantial decreases from baseline in median sCTX and uCTX concentrations at $\mathrm{d} 91$ in the active treatment arms (primary PD endpoint; Table 3); decreases $v$ s. baseline were statistically significant for all dose groups (overall $P<0.0001$ by Kruskal-Wallis test). The median reductions from baseline in SCTX and uCTX concentrations were 56.7 and $54.1 \%$, respectively (150-mg arm) and 40.7 and $34.6 \%$ (100-mg arm), compared with 12.3 and $5.5 \%$ in the placebo arm (PP analysis). The differences between active treatment and placebo in the median reductions from baseline were significant for all but the 50 -mg group $(P<0.001$ by extended Wilcoxon rank-sum test; Table 3$)$. The results of the ITT analysis were similar to those of the PP analysis. Analysis of the AUEC ( $d$
1-91) for relative change (percent $\times$ days) in $\mathrm{SCTX}$ and $\mathrm{uCTX}$ indicated a dose-response relationship (Fig. 2).

\section{$P K s$}

A summary of the PK parameters after the first oral administration of 50,100 , or $150 \mathrm{mg}$ ibandronate is presented in Table 4.

Ibandronate in serum. The mean serum $\mathrm{AUC}_{0-\infty}$ associated with the first dose of each of the monthly dosing schedules (primary PK endpoint) is shown in Fig. 3. As expected, systemic exposure in participants receiving $50 \mathrm{mg}$ ibandronate (50- and 50/100-mg arms) was broadly similar. At higher doses (100 $\mathrm{mg}$ and $150 \mathrm{mg}$ ), however, systemic exposure $\left(\mathrm{AUC}_{0-\infty}\right)$ appeared to increase disproportionately to dose (Fig. 3). Subsequent statistical analysis (ANOVA) of the AUC $_{0-\infty}$ gave mean systemic exposure ratios (relative to the 50-mg dose) of $130 \%$ (95\% CI, $94-180 \%$ ) and $191 \%$ (95\% CI, $138-265 \%$ ) for the $100-\mathrm{mg}$ and $150-\mathrm{mg}$ ibandronate groups, respectively. Given that the CI for the 150-mg-dose group did not contain the equivalence value $(100 \%)$, the null hypothesis of dose proportionality for the $\mathrm{AUC}_{0-\infty}$ between all three groups was rejected $(P=0.0006)$, and it was concluded that the $\mathrm{AUC}_{0-\infty}$ was not dose-proportional among the three dose groups. ANOVA of the secondary PK parameters, serum $\mathrm{C}_{\max }$ and $\mathrm{Ae}$, confirmed this finding. A trend toward an increase in $\mathrm{t}_{1 / 2}$ with increasing dose (Table 4 ) was considered to be a result of low terminal serum concentrations, which approached the limits of assay quantification.

Ibandronate in urine. The overall recovery of ibandronate (Ae) in urine was $0.2-0.4 \%$, with the majority being recovered within the first $6 \mathrm{~h}$ post dose (Fig. 4). No differences were observed in Ae for the first and third dosing cycles for each dosing arm. During the first dosing cycle, Ae was slightly higher in the $150-\mathrm{mg}$ arm $(0.38 \%)$ compared with $100-$ and 50 -mg arms $(0.26-0.29 \%)$. However, in the third dosing cy-

TABLE 3. Median change (\%) from baseline in serum and urine concentrations of CTX at d 91 after monthly treatment with oral ibandronate (PP population)

\begin{tabular}{|c|c|c|c|c|c|}
\hline & Placebo & $50 \mathrm{mg}$ & $50 / 100 \mathrm{mg}$ & $100 \mathrm{mg}$ & $150 \mathrm{mg}$ \\
\hline $\begin{array}{l}\text { sCTX } \\
\text { vs. baseline } \\
\text { vs. placebo } \\
\text { uCTX }\end{array}$ & $-12.3(-27.7,-3.3)$ & $\begin{array}{c}-22.3(-39.6,-9.1) \\
-9.0(-22.2,5.9)\end{array}$ & $\begin{array}{l}-49.6(-61.4,-35.4) \\
-32.8^{a}(-45.6,-16.5)\end{array}$ & $\begin{array}{l}-40.7(-54.0,-25.9) \\
-23.7^{a}(-35.2,-10.4)\end{array}$ & $\begin{array}{l}-56.7(-70.2,-39.7) \\
-38.6^{a}(-50.0,-26.1)\end{array}$ \\
\hline $\begin{array}{l}\text { vs. baseline } \\
\text { vs. placebo }\end{array}$ & $-5.5(-25.9,14.2)$ & $\begin{array}{r}-13.4(-40.9,21.3) \\
-5.3(-26.9,20.6) \\
\end{array}$ & $\begin{array}{l}-54.8(-64.2,-32.7) \\
-40.5^{a}(-58.8,-20.9)\end{array}$ & $\begin{array}{l}-34.6(-58.6,-18.1) \\
-32.0^{a}(-48.9,-14.3)\end{array}$ & $\begin{array}{l}-54.1(-76.4,-42.6) \\
-51.7^{a}(-65.6,-36.4)\end{array}$ \\
\hline
\end{tabular}

Interquartile limits are given in parentheses. Rows for placebo show differences between medians (95\% CI) in the active and placebo groups.

${ }^{a} P<0.001$ for ibandronate $v s$. placebo, extended Wilcoxon rank-sum test. 


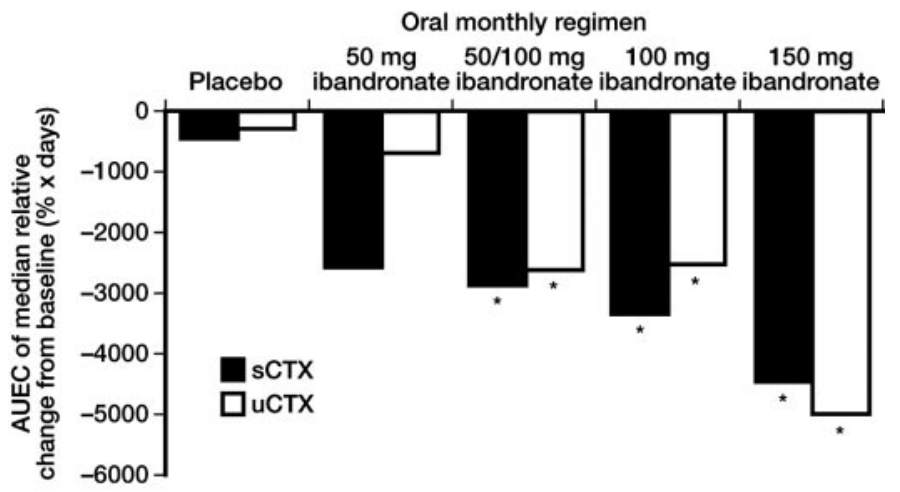

\section{${ }^{\star} P<0.0001$ versus placebo}

Fig. 2. Median values of AUEC, calculated as percentage change between baseline and d 91 in concentrations of sCTX and uCTX after monthly treatment with oral ibandronate (PP population).

cle, Ae was similar among the 150-, 100-, and 50/100-mg arms $(0.34,0.31$, and $0.33 \%$, respectively) but was higher than in the $50-\mathrm{mg}$ arm $(0.18 \%)$. An apparent trend toward a decrease in the $\mathrm{CL}_{\mathrm{R}}$ of ibandronate with increasing dose was observed. However, this was considered to be the result of the incomplete definition of the AUC of ibandronate in plasma at lower doses.

\section{Discussion}

Ibandronate is a potent, nitrogen-containing bisphosphonate with proven antifracture efficacy when administered as a daily (vertebral fracture risk reduction, 62\%) or intermittent oral regimen (vertebral fracture risk reduction, 50\%) with a between-dose interval of more than 2 months to women with postmenopausal osteoporosis (26). Ibandronate has also been shown to provide substantial and comparable increases in BMD at the lumbar spine and hip and decreases in biochemical markers of turnover when administered continuously or less frequently $(26,28)$. A safety profile similar to that of placebo has also been demonstrated in numerous studies of oral ibandronate, independent of the administration schedule and population characteristics (26, 29-33).

In the current study, we explored the feasibility of administering ibandronate as a once-monthly oral regimen in postmenopausal women. Specifically, we explored the tolerability, PD, and PK of three cycles of monthly oral 50, 50/100, 100 , or $150 \mathrm{mg}$ ibandronate, relative to placebo. At the studied doses, once-monthly oral ibandronate was well tolerated, with a safety profile similar to that of placebo. Adverse events were typical of the bisphosphonate class, with no unexpected safety concerns reported. The number of upper

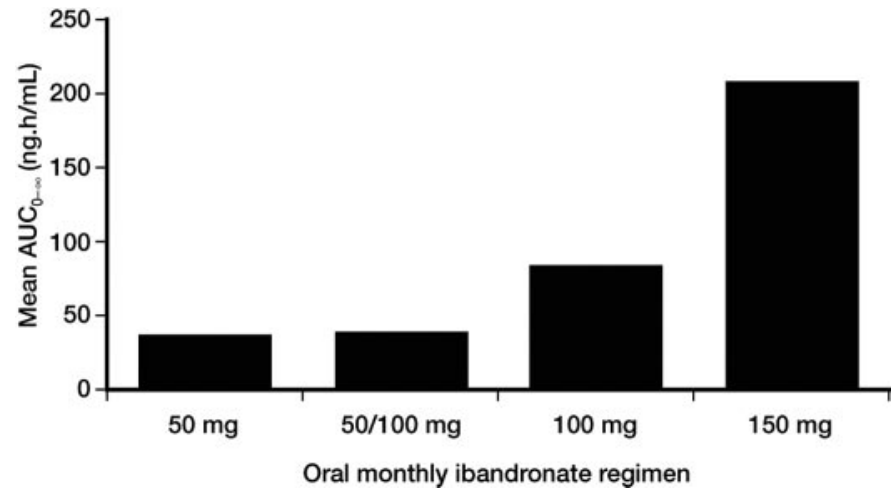

Fig. 3. Mean $\mathrm{AUC}_{0-\infty}$ for monthly oral ibandronate in serum (initial dose only).

GI safety adverse events within $3 \mathrm{~d}$ of dosing was comparable across treatment arms. These findings are consistent with prior studies of oral ibandronate in women with and without postmenopausal osteoporosis, in which oral ibandronate was shown to be extremely well tolerated and to have a safety profile similar to that of placebo when administered continuously $(2.5 \mathrm{mg})$, weekly $(20 \mathrm{mg})$, or intermittently (20 mg every other dose for 12 doses every 3 months) (26, 29-33). A favorable tolerability profile has been observed also in patients with metastatic bone disease receiving high individual and cumulative daily doses of ibandronate: in clinical trials, oral daily ibandronate $(50 \mathrm{mg})$ administered for $96 \mathrm{wk}$ was well tolerated, with a safety profile similar to that of placebo (34).

In addition to its good tolerability, once-monthly oral ibandronate was effective in suppressing bone resorption. At d 91, $30 \mathrm{~d}$ after the final administration of study medication, substantial and significant relative reductions in median sCTX and uCTX levels were observed. Analysis of the AUEC (d 1-91) for the median relative change in SCTX and UCTX, an integrated PD assessment reflecting the total level of suppression over the analysis period rather than at a single time point, indicated a dose-response relationship for monthly oral ibandronate. Thus, whereas acknowledging the limitations of the MOPS study, these findings, especially those in the higher dose-containing arms (100 and $150 \mathrm{mg}$ ), highlight a strong potential for clinically meaningful efficacy with monthly oral ibandronate.

Systemic exposure to ibandronate increased with dose but not in a dose-proportional manner, as shown by calculations of the ratio of dose-normalized AUC values at the higher ibandronate doses relative to the $50-\mathrm{mg}$ value $(130 \%$ for the $100-\mathrm{mg}$ group and $191 \%$ for the $150-\mathrm{mg}$ group). Consequently, a linear association between dose and serum expo-

TABLE 4. Summary of PK parameters after the first oral administration of monthly oral ibandronate [mean (SD)]

\begin{tabular}{|c|c|c|c|c|}
\hline Ibandronate dose & $\mathrm{AUC}_{0-\infty}(\mathrm{ng} / \mathrm{h} \cdot \mathrm{ml})$ & $\mathrm{C}_{\max }(\mathrm{ng} / \mathrm{ml})$ & $\mathrm{t}_{1 / 2}(\mathrm{~h})$ & $\mathrm{CL}_{\mathrm{R}}(\mathrm{ml} / \mathrm{min})$ \\
\hline $50 \mathrm{mg}(\mathrm{n}=18)$ & $37.5(59.2)^{a}$ & $10.7(21.9)$ & $26.9(23.2)$ & $76.8(35.0)$ \\
\hline $50 / 100 \mathrm{mg}(\mathrm{n}=18)$ & $38.1(21.6)$ & $11.7(7.74)$ & $33.4(21.9)$ & $69.5(19.8)$ \\
\hline $100 \mathrm{mg}(\mathrm{n}=36)$ & $84.1(53.6)$ & $22.8(18.9)$ & $58.6(22.5)$ & $59.4(18.4)^{b}$ \\
\hline $150 \mathrm{mg}(\mathrm{n}=36)$ & $208(185)$ & $49.7(44.0)$ & $72.0(15.8)$ & $56.9(16.6)^{c}$ \\
\hline
\end{tabular}

\footnotetext{
${ }^{a} \mathrm{n}=16$.

${ }^{b} \mathrm{n}=35$.

${ }^{c} \mathrm{n}=33$.
} 


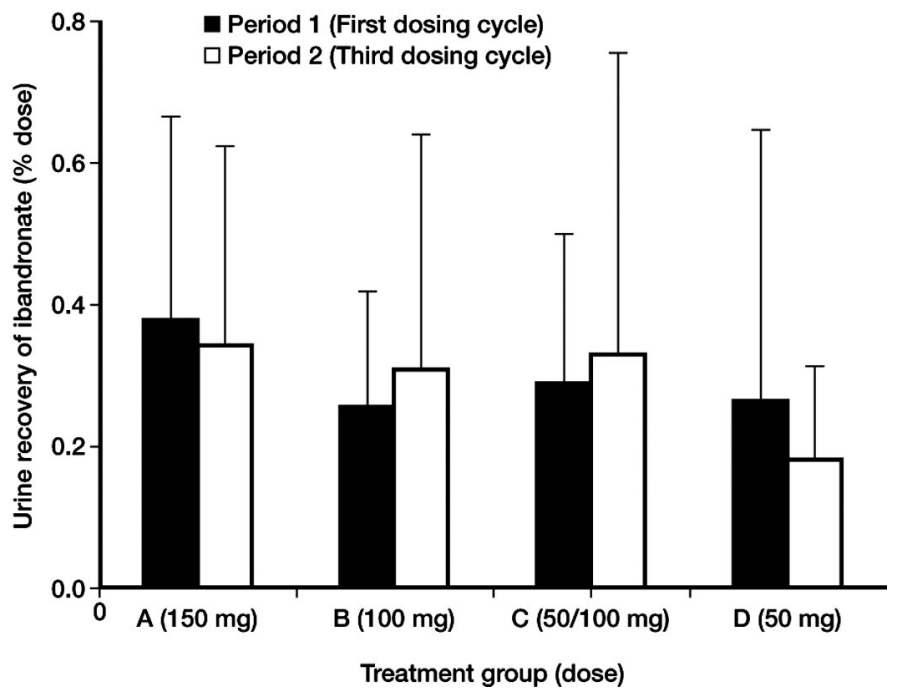

FIG. 4. Mean (SD) urine recoveries (Ae percent) after oral administration of 50,100, or $150 \mathrm{mg}$ ibandronate to postmenopausal women.

sure to ibandronate was not demonstrated at the studied doses. However, consistent with the dose-independent bioavailability reported for alendronate (at doses of up to $80 \mathrm{mg}$ ) (35) and dose-proportional PKs of risedronate (at doses up to $30 \mathrm{mg}$ ) (36), serum exposure with ibandronate is linear up to a 50-mg dose (37). The reason for disproportionate exposure with oral ibandronate at doses greater than $50 \mathrm{mg}$ is unknown. Increased absorption efficiency at high ibandronate doses cannot be completely ruled out based on these data. The $\mathrm{AUC}_{0-\infty}$ for the 50- and 100-mg ibandronate doses was consistent with prior phase I PK studies of oral ibandronate (37).

As previously stated, recent studies have shown that therapeutic adherence with osteoporosis medications, including daily and weekly oral bisphosphonates, is suboptimal (1218). Commonly cited reasons for nonadherence include dosing convenience and/or complexity $(38,39)$ and side effects (38-40). A convenient once-monthly tablet with a favorable safety and tolerability profile may therefore provide adherence benefits in postmenopausal osteoporosis.

The findings of the MOPS study demonstrate that oncemonthly oral ibandronate is well tolerated and efficacious in postmenopausal women. However, given the small number of participants and absence of standardized calcium and vitamin D supplementation in the MOPS study, further evaluation of the once-monthly ibandronate dosing concept is warranted. A large-scale, randomized, double-blind, phase III study [Monthly Oral Ibandronate in Ladies (MOBILE)] will establish the efficacy and safety of 2 yr of treatment with the 100- and 150-mg monthly oral ibandronate regimens in postmenopausal women with osteoporosis. Similar to the studies of oral weekly and daily alendronate (21) and risedronate (22), MOBILE is a noninferiority study, which uses the proven oral daily ibandronate regimen as an active comparator. Vertebral fracture efficacy will be derived if the monthly oral regimens show noninferiority to the oral daily regimen for lumbar spine BMD change (percent) at $1 \mathrm{yr}$. Positive outcomes from this study will likely provide physicians and patients with an additional dosing option for the management of postmenopausal osteoporosis.

\section{Conclusions}

The findings of the MOPS study demonstrate that oncemonthly oral ibandronate dosing is well tolerated and efficacious in suppressing bone turnover in postmenopausal women. However, given the limitations of the MOPS study, additional evaluation of once-monthly ibandronate dosing is warranted. The MOBILE study is evaluating the efficacy and safety of 100- and 150-mg once-monthly oral ibandronate regimens in postmenopausal women with osteoporosis.

\section{Acknowledgments}

Additional investigators and significant contributors to MOPS were Dr. John Lambert (UK), Dr. Christopher Mugglestone (UK), Dr. Graham Mold (UK), Dr. Salvatore Febbraro (UK), and Dr. Jean Fraser (UK).

Received September 3, 2004. Accepted June 14, 2005.

Address all correspondence and requests for reprints to: Professor Jean-Yves Reginster, Unité d'Exploration du Metabolisme de l'Os et du Cartilage, Centre Hospitalier Universitaire Centre Ville, B-4020 Liège, Belgium. E-mail: jyreginster@ulg.ac.be.

This work was supported by F. Hoffmann-La Roche Ltd. (Basel, Switzerland) and GlaxoSmithKline Pharmaceuticals (Collegeville, Pennsylvania).

\section{References}

1. Kanis JA, Delmas P, Burckhardt P, Cooper C, Torgerson D 1997 Guidelines for diagnosis and management of osteoporosis. The European Foundation for Osteoporosis and Bone Disease. Osteoporos Int 7:390-406

2. Melton LJ, Atkinson EJ, O'Fallon WM, Walmer HW, Riggs BL 1991 Longterm fracture risk prediction with bone mineral measurements made at various skeletal sites. J Bone Miner Res 6(Suppl 1):S136 (Abstract)

3. Melton LJ 2003 Adverse outcomes of osteoporotic fractures in the general population. J Bone Miner Res 18:1139-1141

4. Chrischilles EA, Butler CD, Davis CS, Wallace RB 1991 A model of lifetime osteoporosis impact. Arch Intern Med 151:2026-2032

5. Greendale GA, Barrett-Connor E, Ingles S, Haile R 1995 Late physical and functional effects of osteoporotic fracture in women: the Rancho Bernardo Study. J Am Geriatr Soc 43:955-961

6. Cooper C, Atkinson EJ, Jacobsen SJ, O'Fallon M, Melton LJ 1993 Populationbased study of survival after osteoporotic fractures. Am J Epidemiol 137:10011005

7. Browner WS, Pressman AR, Nevitt MC, Cummings SR 1996 Mortality following fractures in older women. The study of osteoporotic fractures. Arch Intern Med 156:1521-1525

8. Ismail AA, O'Neill TW, Cooper C, Finn JD, Bhalla AK, Cannata JB, Delmas P, Falch JA, Felsch B, Hoszowski K, Johnell O, Diaz-Lopez JB, Lopez Vaz A, Marchand F, Raspe H, Reid DM, Todd C, Weber K, Woolf A, Reeve J, Silman AJ 1998 Mortality associated with vertebral deformity in men and women: results from the European Prospective Osteoporosis Study (EPOS). Osteoporos Int 8:291-297

9. Hasserius R, Karlsson MK, Nilsson BE, Redlund-Johnell I, Johnell O 2003 Prevalent vertebral deformities predict increased mortality and increased fracture rate in both men and women: a 10-year population-based study of 598 individuals from the Swedish cohort in the European Vertebral Osteoporosis Study. Osteoporos Int 14:61-68

10. International Osteoporosis Foundation 2001 Osteoporosis in the European community: a call to action.

11. Ray NF, Chan JK, Thamer M, Melton LJ 1997 Medical expenditures for the treatment of osteoporotic fractures in the United States in 1995: report from the National Osteoporosis Foundation. J Bone Miner Res 12:24-35

12. Cramer JA, Amonkar MM, Hebborn A, Suppapanya N 2004 Does dosing regimen impact persistence with bisphosphonate therapy among postmenopausal osteoporotic women? J Bone Miner Res 19(Suppl 1):S448 (Abstract)

13. Ettinger MP, Gallagher R, Amonkar MM, Smith JC, MacCosbe PE 2004 Medication persistence is improved with less frequent dosing of bisphosphonates, but remains inadequate. Arthritis Rheum 50(Suppl):S513 (Abstract)

14. Papaioannou A, Ioannidis G, Adachi JD, Sebaldt RJ, Ferko N, Puglia M, Brown J, Tenenhouse A, Olszynski WP, Boulos P, Hanley DA, Josse R, Murray TM, Petrie A, Goldsmith CH 2003 Adherence to bisphosphonates and 
hormone replacement therapy in a tertiary care setting of patients in the CANDOO database. Osteoporos Int 14:808-813

15. Caro JJ, Ishak KJ, Huybrechts KF, Raggio G, Naujoks C 2004 The impact of compliance with osteoporosis therapy on fracture rates in actual practice. Osteoporos Int 15:1003-1008

16. Yood RA, Emani S, Reed JI, Lewis BE, Charpentier M, Lydick E 2003 Compliance with pharmacologic therapy for osteoporosis. Osteoporos Int 14:965968

17. Clowes JA, Peel NFA, Eastell R 2004 The impact of monitoring adherence and persistence with antiresorptive treatment for postmenopausal osteoporosis: a randomized controlled trial. J Clin Endocrinol Metab 89:1117-1123

18. McCombs JS, Thiebaud P, McLaughlin-Miley C, Shi J 2004 Compliance with drug therapies for the treatment and prevention of osteoporosis. Maturitas 48:271-287

19. Eastell R, Garnero P, Vrijens B, van de Langerijt L, Pols HAP, Ringe JD, Roux C, Watts NB, Cahall D, Delmas PD 2003 Influence of patient compliance with risedronate therapy on bone turnover marker and bone mineral density response: the IMPACT study. Calcif Tissue Int 72:408

20. Claxton AJ, Cramer J, Pierce C 2001 A systematic review of the associations between dose regimens and medication compliance. Clin Ther 23:1296-1310

21. Schnitzer T, Bone HG, Crepaldi G, Adami S, McClung M, Kiel D, Felsenberg D, Recker RR, Tonino RP, Roux C, Pinchera A, Foldes AJ, Greenspan SL, Levine MA, Emkey R, Santora 2nd AC, Kaur A, Thompson DE, Yates J, Orloff JJ 2000 Therapeutic equivalence of alendronate $70 \mathrm{mg}$ once-weekly and alendronate $10 \mathrm{mg}$ daily in the treatment of osteoporosis. Alendronate OnceWeekly Study Group. Aging (Milano) 12:1-12

22. Brown JP, Kendler DL, McClung MR, Emkey RD, Adachi JD, Bolognese MA, Li Z, Balske A, Lindsay R 2002 The efficacy and tolerability of risedronate once a week for the treatment of postmenopausal osteoporosis. Calcif Tissue Int 71:103-111

23. Simon JA, Lewiecki M, Smith ME, Petruschke RA, Wang L, Palmisano JJ 2002 Patient preference for once-weekly alendronate $70 \mathrm{mg}$ versus once-daily alendronate $10 \mathrm{mg}$ : a multicenter randomized open-label, crossover study. Clin Ther 24:1871-1886

24. Kendler D, Kung AW, Fuleihan Gel-H, Gonzalez Gonzalez JG, Gaines KA, Verbruggen N, Melton ME 2004 Patients with osteoporosis prefer once weekly to once daily dosing with alendronate. Maturitas 48:243-251

25. Bauss F, Russell G 2004 Ibandronate in osteoporosis: preclinical data and rationale for intermittent dosing. Osteoporos Int 15:423-433

26. Chesnut CH, Skag A, Christiansen C, Recker R, Stakkestad JA, Hoiseth A, Felsenberg D, Huss H, Gilbride J, Schimmer RC, Delmas PD 2004 Effects of oral ibandronate administered daily or intermittently on fracture risk in postmenopausal osteoporosis. J Bone Miner Res 19:1241-1249
27. Gieschke R, Reginster J-Y 2004 Successful prediction of the effect of oncemonthly oral ibandronate on a marker of bone resorption using clinical trial simulation (CTS). Osteoporos Int 15(Suppl 1):S97 (Abstract)

28. Delmas PD, Recker RR, Chesnut CH, Skag A, Stakkestad JA, Emkey R, Gilbride J, Schimmer RC, Christiansen C 2004 Daily and intermittent oral ibandronate normalize bone turnover and provide significant reduction in vertebral fracture risk: results from the BONE study. Osteoporos Int 15:792-798

29. Riis BJ, Ise J, von Stein T, Bagger Y, Christiansen C 2001 Ibandronate: a comparison of oral daily dosing versus intermittent dosing in postmenopausal osteoporosis. J Bone Miner Res 16:1871-1878

30. Cooper C, Emkey RD, McDonald RH, Hawker G, Bianchi G, Wilson K, Schimmer RC 2003 Efficacy and safety of oral weekly ibandronate in the treatment of postmenopausal osteoporosis. J Clin Endocrinol Metab 88:46094615

31. Ravn P, Clemmesen B, Riis BJ, Christiansen C 1996 The effect on bone mass and bone markers of different doses of ibandronate: a new bisphosphonate for prevention and treatment of postmenopausal osteoporosis: a 1 year, randomized, double-blind, placebo controlled dose finding study. Bone 19:527-533

32. McClung MR, Wasnich RD, Recker RR, Cauley JA, Chesnut 3rd CH, Ensrud KE, Burdeska A, Mills T 2004 Oral daily ibandronate prevents bone loss in early postmenopausal women without osteoporosis. J Bone Miner Res 9:11-18

33. Tanko LB, Felsenberg D, Czerwinski E, Burdeska A, Jonkanski I, Hughes C, Christiansen C 2003 Oral weekly ibandronate prevents bone loss in postmenopausal women. J Intern Med 254:159-167

34. Diel IJ, Body JJ, Tripathy D, Bergstrom B 2003 Oral daily ibandronate in women with metastatic breast cancer: a pooled safety analysis. Proc Am Soc Clin Oncol 22:47 (Abstract)

35. Gertz BJ, Holland SD, Kline WF, Matuszewski BK, Freeman A, Quan H, Lasseter KC, Mucklow JC, Porras AG 1995 Studies of the oral bioavailability of alendronate. Clin Pharmacol Ther 58:288-298

36. Mitchell DY, Eusebio RA, Sacco-Gibson NA, Pallone KA, Kelly SC, Nesbitt JD, Brezovic CP, Thompson GA, Powell JH 2000 Dose-proportional pharmacokinetics of risedronate on single-dose oral administration to healthy volunteers. J Clin Pharmacol 40:258-265

37. Barrett J, Worth E, Bauss F, Epstein S 2004 Ibandronate: a clinical pharmacological and pharmacokinetic update. J Clin Pharmacol 44:951-965

38. Lombas C, Hakim C, Zanchetta JR 2000 Compliance with alendronate treatment in an osteoporosis clinic. J Bone Miner Res 15(Suppl 1):M406 (Abstract)

39. Segal E, Tamir A, Ish-Shalom S 2003 Compliance of osteoporotic patients with different treatment regimens. Isr Med Assoc J 5:859-862

40. Tosteson AN, Grove MR, Hammond CS, Moncur MM, Ray GT, Hebert GM, Pressman AR, Ettinger B 2003 Early discontinuation of treatment for osteoporosis. Am J Med 115:209-216

JCEM is published monthly by The Endocrine Society (http://www.endo-society.org), the foremost professional society serving the endocrine community. 